\title{
Como a convergência de água, efluentes, emissões, energia, eficiência energética e economia de baixo carbono irá impactar o futuro?
}

\author{
Marcos Tadeu Pereira*
}

\section{Introdução}

Talvez o mais importante exercício de futurologia que se possa tentar fazer hoje seja aquele ligado às variáveis mencionadas no título deste artigo: o que irá acontecer com o uso de água, energia e com a geração de efluentes e emissões, e como isso irá impactar a qualidade da vida?

Novas questões entraram na pauta do mundo tecnológico e econômico e são discutidas nos meios de comunicação: sustentabilidade, aumento da temperatura global, emissões de gases de efeito estufa, fontes de energias alternativas, créditos de carbono, reciclagem, falta de água. As notícias que chegam de análises acadêmicas atualizadas trazem preocupações extremas quanto à capacidade do ser humano encontrar soluções para o aumento progressivo e rápido dos problemas ambientais, aliado ao aumento exponencial da população.

As questões ambientais são claramente apontadas no Painel Intergovernamental de Mudanças Climáticas (Intergovernmental Panel on Climate Change (IPCC) $)^{(1)}$, que traça diversos cenários de previsões de elevação de temperatura na Terra nos próximos anos. Por exemplo, no cenário A1F1 (uso intensivo de combustíveis fósseis, na forma que estamos usando), o aumento de temperatura seria de $4^{\circ} \mathrm{C}$ até 2100 em relação a 1999, o que permite traçar previsões muito ruins em termos de impactos para o homem e suas atividades econômicas, e mesmo de sobrevivência da maior parte da humanidade.

Deve-se atentar que os assuntos ambientais relativos a mudanças climáticas provocadas por gases de efeito estufa evoluíram de uma posição inicial de ataque e desacreditação por parte de governos e setores poluidores, para uma situação de ciência sólida, bem conceituada e que deve ser imediatamente tratada, agora aceita quase universalmente, dada a abundância de evidências comprovadas. Ainda há divergências pontuais com relação aos cenários projetados, normalmente restritas a porta vozes de setores e governos interessados em manter os negócios sem modificações, mas mesmo estes setores raramente questionam as evidências.

Para enfrentar este cenário futuro catastrófico diversos países começaram a preparar ações de intervenção e estímulo para diminuir emissões de gases de efeito estufa, diminuir o consumo de energia, regular o uso da água. É notório que estas ações estão interconectadas entre si e convergem: não se altera uma sem provocar mudanças nas outras, e isso é um novo desafio que a tecnologia terá que enfrentar.

Estas ações fatalmente terão eco e efeito no Brasil (um dos grandes emissores de gases de efeito estufa no mundo), e os estudos de como se dará a evolução das necessidades e as ações que poderão ser tomadas são prementes.

Para atuar na interação e convergência entre os processos que envolvam o uso de água, energia e que gerem emissões e efluentes será necessário, entre outras coisas, uma mudança de paradigmas em projetos e operação de empreendimentos.

A mudança de paradigmas virá na forma de novas soluções tecnológicas radicais (que ainda

\footnotetext{
Marcos Tadeu Pereira*

Engenheiro Mecânico e Doutor em Engenharia Mecânica

Professor do Departamento de Engenharia Mecânica da Escola Politécnica da USP

Pesquisador do Laboratório de Fluidodinâmica e Eficiência Energética do IPT

Diretor Técnico do IPT- Instituto de Pesquisas Tecnológicas- entre 2004 e 2009

Autor de cerca de 80 artigos técnicos
} 
nem sabemos quais são), de busca incessante de eficiência energética e de uma economia de baixo carbono, que deverão atuar na convergência e inter-relação entre água, energia, efluentes e emissões.

Como se verá mais adiante, a mudança de paradigmas de projeto e operação de instalações, a eficiência energética e a economia de baixo carbono são condições irremovíveis para uma atuação bem sucedida.

Do que se vê no exterior e nas publicações avançadas, os investimentos na solução das questões ambientais deverão dominar o foco dos investimentos e talvez até boa parte dos investimentos em avanços tecnológicos nas próximas décadas.

\section{O surgimento do conceito de "conver- gência tecnológica"}

Desde o início da revolução industrial, em meados do século XVIII no Reino Unido houve um crescente aumento da especialização científica e tecnológica. Em parte por conta desta especialização extrema, nem sempre a aplicação de tecnologias para a produção analisou de forma ampla todos os aspectos das soluções de cada problema, o que acabou gerando desequilíbrios ambientais e sociais bastante complicados.

Há no mínimo possibilidades não exploradas da convergência de tecnologias e conhecimentos distintos que devem ser consideradas imediatamente.

É interessante ressaltar que esta percepção de necessidade de conhecimentos cruzados, convergentes, começou a nascer com um fato isolado. Em um artigo de 1959, "There's Plenty of Room at the Bottom - An Invitation to Enter a New Field of Physics", Richard Feynman praticamente lançou as bases do que hoje se chama nanotecnologia, com uma série de desafios muito bem colocados em biotecnologia, rearranjo de átomos, miniaturização de computadores, e da necessidade de interação entre eles.

A crescente importância tecnológica da nanotecnologia acabou por confirmar que era imperativo para o desenvolvimento tecnológico que houvesse interação entre áreas que não se conversavam habitualmente, como informática, biotecnologia, nanotecnologia, e teorias do conhecimento, para produzir novas soluções.

Foi criado então o termo convergência tecnológica para designar a interação destes campos. A convergência tecnológica passou a ser co- nhecida pelo acrônimo NBIC (Nanotecnologia, Biotecnologia, Informática e ciência do Conhecimento (cognitive sciences)). Também apareceu o termo Little BANG (Bits, Átomos, Neurônios e Genes), igualmente destinado a auxiliar a compreensão de direcionamento dos esforços para desenvolvimento de tecnologia.

O conceito de "convergência tecnológica" aplicado às relações ambientais

Deve-se considerar que avanços tecnológicos, disruptivos ou incrementais, não ocorrem livremente, sem problemas reais, que podem adiar ou até impedir a implementação de novas tecnologias. Sempre que há avanços tecnológicos e produção intensa aparecem problemas (emissões, efluentes, disponibilidade insuficiente ou mesmo falta de energia ou de água, etc) que têm que ser resolvidos ou amenizados e que podem demandar enorme esforço tecnológico e financeiro. Estes problemas podem representar tanto oportunidades de avanço quanto impeditivos ou mesmo bloqueios totais a algumas tecnologias.

Houve progresso notável em tecnologias de ponta, o homem chegou à Lua, produz modificações por meio de engenharia genética, a medicina e produção de remédios avançaram de forma impressionante, as comunicações e a informática transformam o mundo. Por outro lado, na outra ponta, 884 milhões de pessoas não usam fontes adequadas de água potável ${ }^{(2)}$, 2,6 bilhões de pessoas não possuem acesso a instalações sanitárias adequadas ${ }^{(2)}$. A emissão de gases de efeito estufa nas atividades humanas está causando problemas ambientais que em algumas décadas podem ser catastróficos: foram emitidos 49,0 Gton $\mathrm{CO}_{2} \mathrm{e}$ (bilhões de toneladas de gases de efeito estufa com efeito equivalente ao do CO2, incluindo este gás) em $2004^{(1)}$.

Apesar de amplamente ancorado na energia fóssil do petróleo, o mundo terá óleo abundante por talvez mais 40 anos, iniciando então o de-

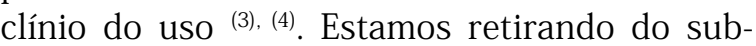
solo em ritmo alucinante (desde 1850) carbono (óleo, gás e carvão) que a natureza levou cerca de 600 milhões de anos para "enterrar", e emitindo isto tudo de volta para a atmosfera em um período muito curto, o que está gerando desequilíbrios muito sérios.

Se nada for feito e continuarmos o "business-as-usual", deve-se contar com a possibilidade de aumento médio de $4^{\circ} \mathrm{C}$ na temperatura da Terra 
até 2100, como comentado anteriormente.

Deve-se chamar atenção para o que se poderia denominar "âncoras ambientais", que representam as condições objetivas que impedem o avanço exponencial da evolução tecnológica e que se apresentam na forma da degradação ambiental. A degradação e deterioração da qualidade da água e do ar e o colapso ou falta de energia representam estas âncoras no momento.

Para facilitar a discussão propõe-se o uso do acrônimo WEAQs (Water, Energy, Emissions, Effluents, Air Quality) para designar as "âncoras", as "fraquezas" que o desenvolvimento tecnológico possui e que temos que aprender a respeitar e a vencer para melhorar a qualidade de vida, face às agressões que o progresso sem estes balizamentos imporia ao planeta e a quem vive nele.

Deve-se pensar como realizar projetos e operar instalações que possibilitem a melhora da qualidade, do uso e da distribuição de água (Water, o W do WEAQs); que levem a um uso da energia da forma mais eficiente possível (Energy, o E do WEAQs), e que contribuam para a diminuição do efeito estufa decorrente da emissão de gases e efluentes e suas consequências (Emissions, Effluents and Air Quality, o EAQ do WEAQs). $O$ cuidado a ser tomado é que deve-se sempre entender a convergência destes fatores: não se mexe em um sem modificar os outros.

Como se percebe, aproveitando o conceito de Convergência Tecnológica, utilizado inicialmente para as tecnologias de desenvolvimento disruptivo e rapidíssimo esperado para os próximos anos em nanotecnologia (NBICs), estamos propondo o uso do termo WEAQs para representar a convergência dos "complicadores" involuntários da ação humana: água, energia, emissões, efluentes e qualidade do ar.

A figura 1 mostra como o fluxo dos processos tecnológicos (incluindo indústria, agropecuária e o setor de comercio, escritórios e governo)

Figura 1- Variáveis convergentes sobre Processos (Industriais, Agropecuários e Institucionais). Observar as ações relacionadas ao meio ambiente e energia

\section{Convergência WEAQs (water, energy, efficiency, emissions, air quality)}

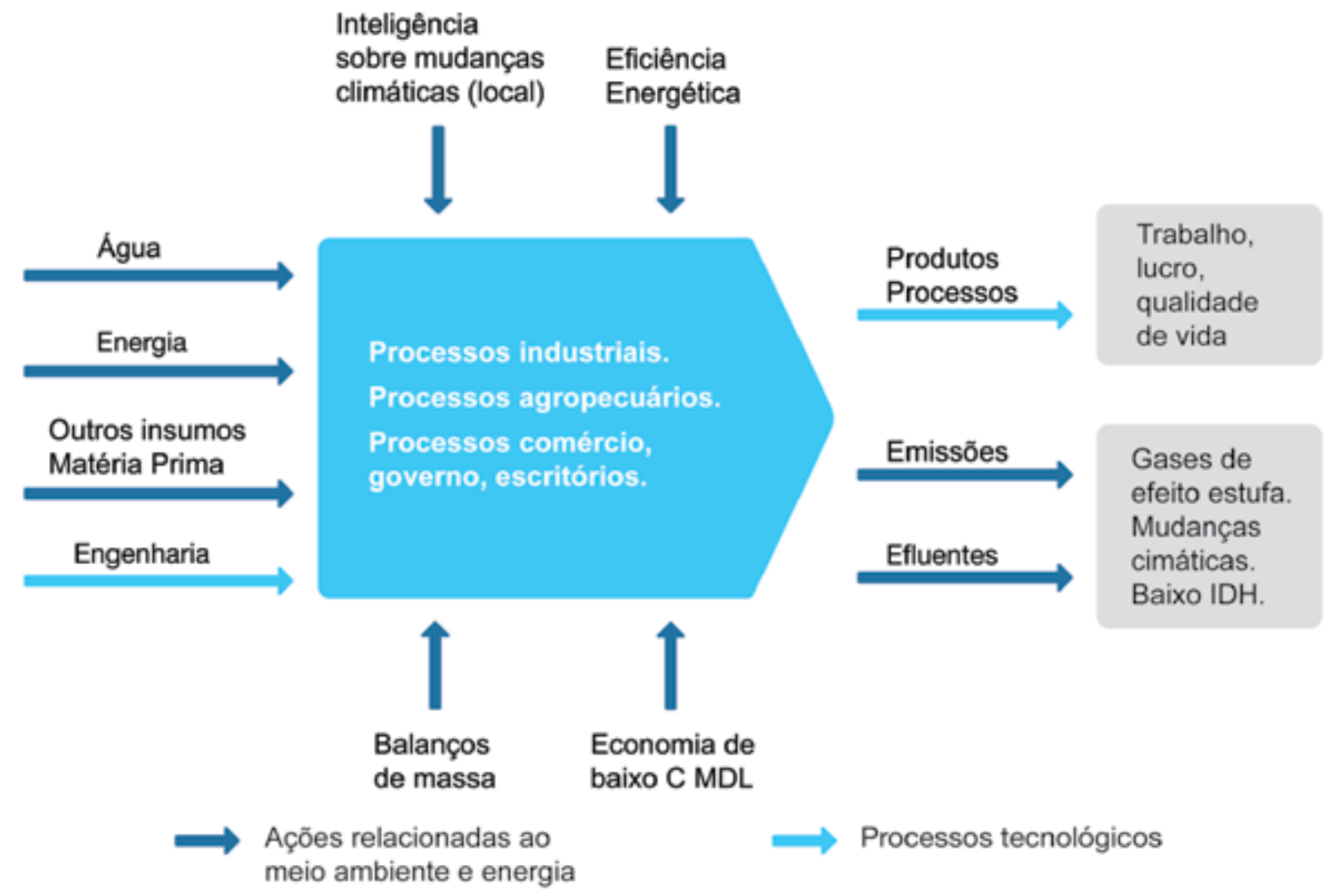

Figura: variáveis convergentes sobre Processos (industriais, agropecuários e institucionais).

Observar as açōes relacionadas ao meio ambiente e energia. 
está cercado e depende da convergência das variáveis energéticas e ambientais.

Deve-se atentar que estes problemas devem ser atacados holisticamente, e pode-se utilizar este conceito com algumas vantagens estratégicas neste momento.

\section{Benchmarking: alguns dados que justifi-} cam a preocupação com a convergência destes temas ambientais

\section{Água e energia}

A energia consumida no mundo inteiro para a distribuição de água - mais de $7,3 \times 10^{12} \mathrm{kWh}$ (base anual), é aproximadamente a quantidade total de energia usada conjuntamente por Japão e Taiwan, e é da ordem de $7 \%$ do consumo mundial (5). O número é muito elevado e gera, na maior parte dos países, graves problemas ambientais devido à emissão de gases de efeito estufa, porque a energia elétrica é na maior parte das vezes gerada pela queima de combustíveis fósseis.

Artigos recentes mostram que o setor industrial de países desenvolvidos consome entre 35 e 40\% de toda energia e desta porcentagem entre 27 e $33 \%$ são consumidos por bombas ${ }^{(6)}$. Stone afirma que o desperdício de energia em sistemas de bombeamento é tão sério nos EUA que pode ser muito maior que qualquer economia de energia que aquele país venha fazer ${ }^{(6)}$.

Esta afirmação potente deve estimular a pensar um pouco mais sobre o assunto: o consumo de energia, na maioria dos sistemas de água em todo o mundo, poderia ser reduzido em mais de 25\%, na média, por meio de ações de eficientização. Pode-se melhorar a eficiência de bombas em até $4 \%$, mas o maior potencial de ganhos de eficiência está nas mudanças realizadas nos sistemas de bombeamento. Economia de energia entre 30 e $50 \%$ pode ser efetivada por meio de mudanças de equipamento ou do sistema de controle $^{(6)}$. Ou seja, há um potencial imenso e francamente inexplorado de economia de recursos e de energia, se forem levadas em consideração apenas as modificações em sistemas de bombeamento.

Apenas para exemplificar, no estado de São Paulo cerca de $2 \%$ da energia elétrica total é consumida pela maior empresa de água e esgoto, quase que na totalidade em operações de bombeamento.

A figura a seguir mostra a previsão do uso de energia pelo setor de água na Inglaterra. A curva inferior representa a meta de aumento de consumo de energia até $2050{ }^{(7)}$, e a linha superior mostra a previsão de aumento do consumo a partir do consumo atual. Vê-se que a meta só será atingida se houver mudanças radicais e incorporação de novas tecnologias.

É inevitável o Brasil passar por esta situação que a Inglaterra aponta no gráfico, pois aparentemente o setor de saneamento básico brasileiro perde por vazamentos uma alta porcentagem de toda a água tratada (há informações de perdas de mais de $35 \%$ em certos casos), devendo-se

Figura 2- Previsão de aumento do uso de energia pela indústria da água

(British Water energy conference, 25 march 2009, Issy Caffor, de Environmental KTN Energy Efficient Water \& Wastewater Treatment) -Baseado no aumento previsto no uso de água pelos gerentes de energia da indústria de água

\section{Previsăo de aumento do uso de energia \%}

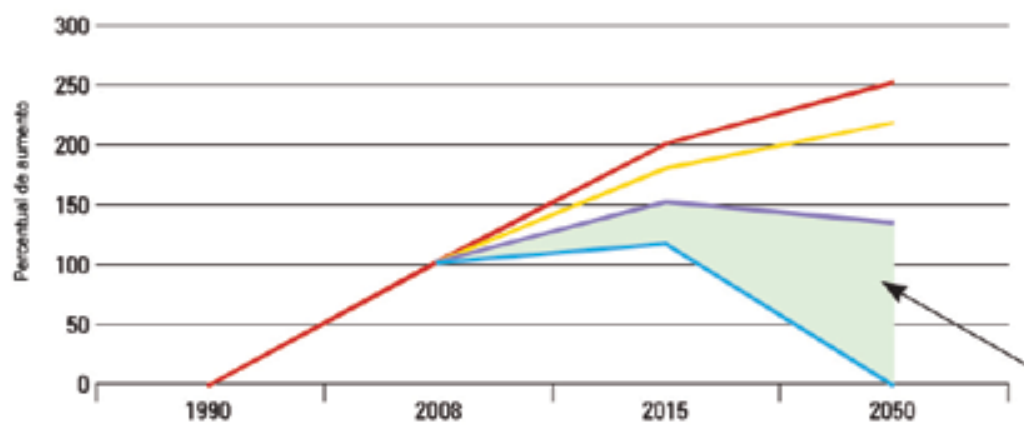

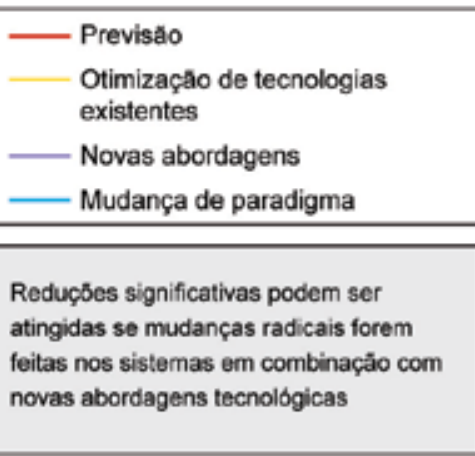


também levar em consideração que a produção de água tratada consome muita energia também.

A situação deverá se complicar ainda mais em nosso país porque as leis ambientais estão ficando mais severas e isso exigirá aumento do número de equipamentos de tratamento da qualidade da água e de esgoto e melhora na universalização destes serviços, com consequente aumento do consumo de energia, e isto sem considerar o aumento do número de pessoas atendidas por saneamento básico.

Tudo isso poderá exigir novas tecnologias, eventualmente disruptivas, para realizar os processos com maior eficiência energética.

\section{Emissões, água e energia}

O cenário de aumento de gastos energéticos associados ao aumento de emissões é um pesadelo para quase todos os países. Até mesmo no Brasil, com sua matriz energética muito favorável e "limpa", a situação é preocupante.

Para exemplificar, no estado de São Paulo existe lei que instituiu a Política Estadual de Mudanças Climáticas - PEMC, que determina que o nível de emissões no setor industrial chegue a 2020 com 20\% menos emissões que no ano de 2005. Isto representa problemas de toda ordem: em 2005 a produção industrial estava em seu nível mais baixo, e o simples crescimento significativo posterior de setores como os de cimento, químico, petróleo, etc já torna muito difícil atender esta meta, sem estudos aprofundados e sem novas tecnologias, que ainda não foram desenvolvidas. Este é um problema de grandes dimensões colocado e que precisa ser resolvido

Há outros exemplos, no exterior. Para enfrentar a questão ambiental decorrente das emissões, o Reino Unido determinou que será necessária uma redução muito expressiva da emissão de carbono nos próximos anos, apesar do aumento significativo do consumo de energia previsto para o período. Em 2006 as emissões, em milhões de toneladas de gás carbônico equivalente, distribuídas por setores, foram as seguintes: ${ }^{(7)}$

- Aviação internacional e navios: 42

- Gases de efeito estufa não $\mathrm{CO}_{2}$ : $\quad 98$

- $\mathrm{CO}_{2}$ : $\quad 22$

- Indústria (calor e processos industriais): 108

- Aquecimento residencial e comercial: 103

- Transporte doméstico: 134

- Geração de eletricidade: 184
Total gerado em 2006: 691 milhões de toneladas de $\mathrm{CO}_{2}$ e. Meta para 2050: 159 milhões de toneladas $\mathrm{CO}_{2} \mathrm{e}$, o que mostra a necessidade de cortar 77\% das emissões de 2006, até 2050.

Para atingir esta meta é evidente que deverá haver um esforço enorme de governo e sociedade.

Deve-se mencionar que a indústria da água naquele país consome aproximadamente $3 \%$ da eletricidade gerada, o que significa $5,52 \mathrm{MtCO}_{2}$, ou menos de $1 \%$ do total. O que é preocupante é que, desde a privatização, a compra de energia por parte das empresas de saneamento aumentou cerca de 50\% para água e 300\% para esgoto $^{(7)}$, aumentos devidos ao tratamento mais sofisticado para atender a demandas regulatórias ordenadas para proteção ambiental.

Para efeito de comparação, nos EUA o consumo de energia nas instalações de água e esgoto gera o equivalente a 34 milhões de toneladas de dióxido de carbono equivalente $\left(\mathrm{CO}_{2} \mathrm{e}\right)$ de emissões de gases de efeito estufa. ${ }^{(8)}$

No Brasil devemos certamente nos preparar para gastar mais energia e recursos no tratamento de água e esgoto.

\section{Dados gerais na indústria}

Aparentemente o investimento em recursos relacionados à eficiência energética é a melhor aposta possível neste momento, como mostrou David Rodgers, Secretário Assistente Executivo de Eficiência Energética do Departamento de Energia dos EUA, na palestra intitulada "Prioritization of Energy Efficiency" apresentada no evento "International Policy Leaders Dialogue" de 25 de setembro de 2008, da Alliance to Save Energy. A conclusão é que a melhora da eficiência energética nos EUA pode simplesmente atender a toda a demanda de crescimento de energia naquele país entre 2010 e 2030. Devemos estar muito atentos a isso no Brasil, pela oportunidade de avanços tecnológicos.

Empresas começam a se movimentar no sentido de colocar os assuntos relativos ao meio ambiente em seus planos de negócios. Veja-se o exemplo da Petrobras, que em 2009 apresentou seus três eixos-chave para as demandas para tecnologia:

Expansão dos limites (pré-sal, novas fronteiras, etc)

Agregação de valor e diversificação de produtos 
Sustentabilidade (gerenciamento de água e efluentes, gerenciamento de $\mathrm{CO}_{2}$ e outras emissões e eficiência energética)

Para mostrar mais uma vez como estudar e resolver a convergência de água, energia, emissões é fundamental, sabe-se que na exploração de petróleo encontra-se água armazenada em formações subterrâneas e é trazida à superfície com óleo e gás, sendo de longe o maior subproduto associado com a produção. O gerenciamento da água produzida trás desafios e custos elevados, e estudos de $2003{ }^{(9)}$ estimam que em média são produzidos desta forma cerca de 33 milhões de $\mathrm{m}^{3}$ de água por dia em todo mundo, cerca de 12,2 bilhões de $\mathrm{m}^{3}$ por ano. Sabe-se ainda que cada litro de produto processado em refinarias consome cerca de 2 litros de água, o que também pode ser estudado dentro da ótica da convergência tecnológica.

De acordo com o World Bank, a queima e vazamento de gases em "flares" representam cerca de 150 bilhões de $\mathrm{m}^{3}$ de gases por ano, equivalente a $30 \%$ do consumo de gás natural nos EUA. ${ }^{(10)}$

Relatório da McKinsey de 2007 (11) aponta que investimentos anuais de US\$ 170 bilhões até 2020 seriam suficientes para capturar a oportunidade de produtividade de energia entre todos os usuários no mundo, sendo que o setor industrial precisaria de US\$ 83 bilhões por ano deste total. As regiões em desenvolvimento representariam $80 \%$ das oportunidades no setor industrial. Afirmam ainda que a produtividade de energia também apresenta a melhor relação custo benefício para reduzir emissões globais de gases de efeito estufa (GHG). Adicionalmente, seriam evitados investimentos em infraestrutura de energia. A Agência Internacional de Energia (IEA) estima que, na média, cada dólar adicional gasto com equipamento, dispositivos e edifícios mais eficientes evitam mais que US\$2 em investimentos no suprimento de eletricidade.

\section{O quadro das variáveis a serem contro- ladas}

Os assuntos itemizados a seguir são variáveis importantes nos processos industriais, e cujo controle pode diminuir e/ou reverter a situação de comprometimento face ao aquecimento global:

$$
\text { - Água }
$$

- Emissões

- Efluentes

- Energia

- Eficiência Energética

- Economia de baixo carbono

- Perdas e Vazamentos

- Inteligência sobre mudanças climáticas, aplicada localmente.

Água é o mais importante recurso natural, em vias de esgotamento em vários lugares, e que participa de praticamente qualquer processo industrial, em vários deles em quantidades muito grandes. Deve-se analisar no Brasil a relação entre consumo de água, de energia e as emissões e efluentes em processos industriais, na agropecuária e na mineração. Qual é a "pegada" (footprint) de água e de $\mathrm{CO}_{2}$ e nestes processos? Quanto se perde de água tratada e energia em vazamentos?

Em termos de emissões, os processos de medição e verificação ainda não são nem de longe satisfatórios, apesar de avanços verificados. Não há ainda uma cultura sólida e disseminada entre os geradores de emissões no sentido de medir e verificar corretamente o que ocorre, talvez em função das grandes dificuldades tecnológicas para a realização destas medidas, e do estágio ainda não totalmente evoluído da cultura deste tipo de medição no Brasil. Por exemplo, ao que se saiba não há nenhum aparelho "Lidar" em operação no país, para medir à distância a concentração e composição de gases emitidos por flares ou chaminés. As avaliações de incertezas de medição nos processos atualmente utilizados também são insatisfatórias, o que pode dar origem a grandes erros de julgamento. Outros pontos a serem levados em consideração são as emissões de origem agropecuária e em queimadas no norte, que acabam por prejudicar seriamente os esforços que vierem a ser feitos na contenção de emissões de origem industrial.

Na questão de efluentes, há um largo caminho à frente. Em grandes cidades, por exemplo, o esforço organizado ainda é insuficiente para avaliar a origem do lançamento de esgotos em cursos d'água ou em galerias de águas pluviais, o que torna os rios inacreditavelmente poluídos. Rios que muitas vezes são o destino de esgoto in natura ou pouco tratado. Aí se tem uma boa questão de como a convergência de água, efluentes e energia se dá, pois a quantidade de 
energia para tratar e recuperar isso tudo não está sendo considerada de uma maneira abrangente. Falta no país, por exemplo, um estudo que parametrize corretamente a saída de esgoto esperada em função de produção, consumo de energia elétrica, área ocupada, etc em determinados setores industriais. Há uma quantidade desconhecida, mas certamente muito grande, de lançamentos clandestinos e/ou uso ilegal de água, retirada do subsolo sem comunicação às autoridades ou compra de água por outros meios que não o de pipelines, o que implica as empresas que compram pouca água da rede pública, mas despejam várias vezes este volume no esgoto e não pagam esta diferença.

A energia é uma questão que possui uma quantidade adequada de institutos, universidades, empresas e agências de governo que se dedicam ao assunto já com competência, muito em função do sucesso do Brasil na exploração da energia de biomassa, e devido à sua matriz energética "mais limpa", onde a geração de energia por combustíveis fósseis é proporcionalmente menor que em outros países.

O tema da eficiência energética está em seu início no Brasil, sendo mais abordado no momento pelo sistema Procel-Eletrobras, mas ainda está muito aquém do envolvimento que se espera nos vários setores industriais. A abordagem no Brasil ainda tem um viés muito grande nas aplicações elétricas, devido ao pioneirismo do sistema Procel, e muitas empresas ainda se limitam a estudos sobre melhor uso de energia em horários de operação selecionados para aproveitar tarifas elétricas mais favoráveis. Há um universo de oportunidades a ser aberto, ou no mínimo melhor explorado do que vem sendo: questões térmicas (eficiência de fornalhas, caldeiras, fornos, motores de combustão), eficiências em bombeamentos e em equipamentos (bombas, ventiladores, compressores, turbinas, perda de carga em dutos, torres de resfriamento, turbinas eólicas, válvulas, eficiência de reservatórios térmicos e painéis solares; eficiência de hélices e forma de cascos de navios, etc).

A economia de baixo carbono representa um assunto novo e com imenso potencial, para um conjunto de medidas a serem tomadas pela sociedade para diminuir a emissão de carbono para o meio ambiente. São necessários mais estudos de consumo de energia por se- tor econômico e analises de alternativas (como combustíveis alternativos, integração de alternativas, desenvolvimento de métodos limpos, suprimento descentralizado de energia, uso de hidrogênio, etc). Para sair do simples discurso, há necessidade de desenvolver ações finalísticas, ou seja, diretamente medindo, verificando e finalmente propondo soluções de forma organizada.

Perdas e vazamentos são fatores importantíssimos de agressão ao meio ambiente e de perda de energia. Empresas de saneamento perdem entre 18 e $30 \%$ de toda a água que tratam, por vazamentos. Isto representa uma sangria de recursos e um desperdício vital, uma vez que água já é um bem escasso, e depende de energia para ser tratada e movimentada. No caso de petróleo, gás e seus derivados, os vazamentos representam adicionalmente riscos de segurança e ambientais muito importantes.

Inteligência sobre mudanças climáticas, aplicada localmente. Este é um assunto que precisa ser desenvolvido. Já há competência no país para abordagens macro ou global, mas aparentemente não se desenvolveu o campo da aplicação local dos conceitos. Como as empresas brasileiras estão se preparando para os tempos de mudanças climáticas em suas unidades industriais? Como se poderá ajudá-las?

\section{Saídas e caminhos}

Como se mostrou, o assunto das mudanças climáticas é muito importante, e pode ser o maior desafio, com origem nas ações do homem, que a humanidade terá que enfrentar.

Os recursos que deverão ser dispendidos nas próximas décadas para amenizar ou eliminar os problemas antropogênicos relacionados às mudanças climáticas deverão ser massivos e afetarão todos os governos, empresas e sociedades.

Para aproveitar melhor estes recursos, pode-se entender que as seguintes linhas gerais devam (algumas delas já o são) ser atacadas no Brasil:

Entender e investir na otimização da convergência entre água, energia, emissões.

Investir na melhora da eficiência energética de projetos e processos, com metas.

Estimular a eficiência energética em bombeamentos.

Estudar as perdas de carga reais nas tubulações empregadas no Brasil. 
Formar engenheiros nas escolas e treinar engenheiros e gerentes no uso de eficiência energética em suas atividades.

Estabelecer índices e medições

Entender e investir na otimização da convergência entre água, energia, emissões.

Tem-se de um lado as variáveis convergentes - água, energia, emissões, efluentes, perdas e vazamentos - intimamente ligadas e que precisão ser "solucionadas" de forma integrada, e outro lado, possíveis formas de abordar e resolver estes problemas - eficiência energética, balanços de massa, economia de baixo carbono, inteligência local sobre mudanças climáticas.

Esta noção da convergência e entrelaçamento dos problemas e soluções ligados a estas variáveis deverá ser explorada e até se chegar a uma mudança de paradigmas nos projetos e processos. Ou seja, a eficiência energética, o uso eficiente de água e baixa emissão de carbono e efluentes deverão ser metas importantes e identificadas em qualquer projeto e processo.

Deve-se trabalhar mais na direção da chamada "Triple bottom line" no demonstrativo de balanços de empresas: ou seja, as empresas devem mostrar os aspectos econômicos, ambientais e sociais de seus negócios. A "triple bottom line" ainda é difícil de ser medida (exceto obviamente os seus aspectos econômicos) e é voluntária (ou seja, empresas apresentam seus demonstrativos ambientais e sociais mais como uma medida de demonstração de suas preocupações e boa vontade nestes assuntos). Talvez se devessem estabelecer regras claras e metodologias de como expressar estes assuntos de forma objetiva, mesmo sabendo das dificuldades de se expressar investimentos ambientais e sociais em termos financeiros.

Investir na melhora da eficiência energética de projetos e processos, com metas.

A forma mais eficiente de redução de emissões e de economia de energia é a eficiência energética: o CEO da Chevron, David O'Reilly, apontou que eficiência energética é a nova forma de energia mais barata que existe ${ }^{(11)}$. Como mostrado anteriormente, segundo Rodgers $^{(12)}$, a melhora da eficiência energética nos EUA pode simplesmente atender a toda demanda de crescimento de energia naquele país entre 2010 e 2030. Relatório recente da
McKinsey de 2007 afirma que é possível cortar o crescimento da demanda projetada global de energia até 2020 pelo menos à metade ao se capturar oportunidades para aumentar a produtividade de energia.

Todas estas referências apontam sem dúvida na direção da eficiência energética como a principal ferramenta de operação para ajudar a resolver a intrincada convergência das variáveis água, energia, emissões, efluentes, perdas e vazamentos.

A eficiência energética pode ser uma forma eficiente e estratégica para trabalhar na direção da "triple bottom line".

O investimento em eficiência de energia já é e pode se consolidar em uma estratégia sólida de negócios no ambiente atual de manufatura.

Estimular a eficiência energética em bombeamentos.

Embora a busca de eficiência energética seja muito mais comum em processos de natureza térmica, estes já possuem ampla literatura e diversos grupos atuando. A oportunidade mais chance de crescimento rápido neste momento talvez seja a representada pelos bombeamentos.

Conforme mostrado no início do artigo, Stone $^{(6)}$ afirma que o desperdício de energia em sistemas de bombeamento é tão sério nos EUA que pode ser muito maior que qualquer economia de energia que aquele país venha fazer. Este é um bom motivo para começar a olhar com atenção os sistemas de bombeamento, pois as questões de bombeamento são muito importantes e bastante negligenciadas ou simplesmente desconhecidas.

A literatura recente mostra que trocar uma bomba pode melhorar em até $4 \%$ a eficiência de uma instalação, mas mudar a operação, melhorar as tubulações pode economizar em média mais de $30 \%$. Isto por si só justifica a necessidade de mudanças de paradigmas no projeto e operação de estações de bombeamento.

Estudar as perdas de carga reais nas tubulações empregadas no Brasil.

Este tema também trata de mudanças de paradigmas: o cálculo das perdas hidráulicas nas tubulações é realizado com equações que foram desenvolvidas na Europa e EUA, para um conjunto limitado de dutos e rugosidades, na década de 1930. 
Estes dados foram trabalhados e ajustados nas equações de Colebrook e diagrama de Moody, para trechos retos de tubulação, e avalia-se que as incertezas associadas a cálculos de perda de carga em trechos retos de dutos sejam da ordem de $15 \%$. No caso das conexões, estudos mais recentes realizados no exterior mostraram variações de até 250\% entre resultados de diversas origens para conexões assemelhadas.

Aparentemente os projetos vêm sendo realizados com um superdimensionamento da avaliação da perda de carga real, o que leva a superdimensionamento das bombas e necessidade de estrangulamentos com válvulas para colocar a bomba em seu ponto correto de operação.

Como se percebe há aqui um excelente caminho a percorrer, talvez a ser iniciado com as seguintes ações:

Realizar experimentos com dutos e conexões brasileiras, com o levantamento de novas equações para perda de carga, novos coeficientes de perda de carga, novos valores de rugosidade, para trechos retos e conexões;

Divulgação de novos paradigmas de projetos hidráulicos (eficiência como baliza), e do uso de Avaliação de Ciclo de Vida (LCA) como ferramenta nos projetos.

Novo livro ou manual sobre perdas de carga e cálculo hidráulico, com disseminação nas escolas de engenharia.

\section{Formar engenheiros nas escolas e treinar engenheiros e gerentes no uso de eficiência energética em suas atividades.}

A questão de melhorar a eficiência energética passa pela formação escolar de engenheiros e quadros gerenciais, que ainda não estão sendo capacitados a projetar e operar instalações dentro de novos paradigmas: deve-se cumprir a função tecnológica desejada, mas sempre com a máxima eficiência energética, que deve ser o balizador mais importante nos processos e projetos. Os engenheiros não estão sendo formados observando paradigmas de projeto que cumpram as necessidades técnicas, mas dentro de parâmetros de eficiência energética, com equações e coeficientes atualizados, e análise criteriosa do custo de ciclo de vida da instalação.

Quando o foco for bombeamentos, o problema cultural nas instalações é sempre difícil de tratar, aqui e no exterior. Geralmente os engenheiros e gerentes das instalações de bombeamento têm a preocupação (justificável) de manter a planta em operação, entregando fluidos na quantidade e condições desejadas pela produção, e o olhar sobre a eficiência energética do processo é quase inexistente.

\section{Estabelecer índices e medições}

Devem ser desenvolvidos índices de energia confiáveis por setor e atividade industrial. Estes índices parametrizados (por exemplo, $\mathrm{m}^{3}$ / $\mathrm{kWh}$ ), poderão dar importantes indicações comparativas para a alta gerência sobre o comportamento de instalações de mesma natureza, e de como se poderiam melhorar as instalações com índices piores.

Devem ser desenvolvidas atividades corretamente dimensionadas de M\&V, Medição e Verificação. Sem medições realizadas corretamente, nenhuma ação de correção é possível, e há muitos problemas ao se medir parâmetros de instalações de bombeamento. Não adianta muito comprar e instalar inversores de frequência para melhorar a operação, se são perdidos 35\% da água produzida (que utiliza muita energia) em vazamentos.

\section{Conclusão}

De um modo geral a estes assuntos ambientais dentro do setor industrial estão sendo ofertadas no momento no Brasil apenas ações pontuais (normalmente apenas de medição), sem que se percebam o nexo com o problema maior, do aquecimento global, e as amplas correlações, convergências e oportunidades entre água, energia, emissões, efluentes, eficiência energética e economia de baixo carbono.

Acredita-se que em alguns anos ou década, estes assuntos poderão dominar a agenda tecnológica do país, dados a importância do assunto e as movimentações que já se verificam no setor tecnológico em nações desenvolvidas.

O elemento de ligação ou de ataque a estas variáveis parece ser a eficiência energética, que usa como ferramentas de análise balanços de massa e de energia, suportados por métodos sólidos de medição.

Particularmente setores que utilizam intensivamente bombeamentos podem se beneficiar muito dos caminhos levantados neste artigo. 


\section{Referências}

(1) Climate change 2007: Sinthesis report. IPCC. Acessado via http://www.ipcc.ch/pdf/ assessment-report/ar4/syr/ar4_syr.pdf. em novembro de 2012 .

(2) Progress in sanitation and drinking water: 2010 update. WHO/UNICEF Joint Monitoring Programme for Water Supply and Sanitation.. Acessado via http://www.wssinfo.org/fileadmin/user_upload/resources/1278061137-

-JMP_report_2010_en.pdf em novembro de 2012

(3) World Fossil Fuel Projection and Projected Depletion - White paper The Colorado River Commission of Nevada, March 2002. Acessado em novembro de 2012 via http://crc.nv.gov/ docs/world\%20fossil\%20reserves.pdf

(4) Forecasting the Permanent Decline in Global Petroleum Production. Marie Plummer Minniear. University of Toledo, Geology Department, Toledo, Ohio 43606. Acessado em novembro de 2012 via http://www.theoildrum. com/node/5956

(5) Água e energia - Aproveitando as oportuinidades de eficientização de água e energia não exploradas nos sistemas de água municipais Allience to save energy e Institute of International Education. Acessado em novembro de 2012 via http://www.lenhs.ct.ufpb.br/html/downloads/livros/agua_energia/aguaeenergia.pdf

(6) Tom Stone. The impact of the Energy Policy Act. World Pumps, pg 30-33, April 2009. http://www.worldpumps.com/view/4076/ the-impact-of-the-us-energy-policy-act-on-the-pumps-industry/

(7) British Water - Annual Review 2009. Consultado em 6 de dezembro de 2012 no site: http://content.yudu.com/Library/A1o7ie/BritishWaterAnnualRe/resources/index.htm?ref errerUrl=http\%3A\%2F\%2Fwww.yudu.com\%2F item\%2Fdetails\%2F181625\%2FBritish-Water-Annual-Review-2009

(8) Biehl, William H.; Inman, A. Julie. Energy optimization for water systems. Journal AWWA, 102.6 - june 2010 pp 50-55

(9) Arnold, R. et al. Managing water - from waste to resource. Acessado no site seguinte em 6 de dezembro de 2012. http://www.slb.com/ /
media/Files/resources/oilfield_review/ors04/ sum04/04_managing_water.pdf

(10) FNI Report 13/2010 (Fridtjof Nansen Institute) Associated Petroleum Gas in Russia - Reasons for non utilization - Roland, T.H.. on line version 978-827613-601-2, conforme consultada em 6 de dezembro de 2012 http://www. fni.no/doc\&pdf/FNI-R1310.pdf

(11) The case for investing in energy productivity. Mackinsey Global Institute, February 2008, conforme site visitado em 6 de dezembro de 2012: http://www.mckinsey.com/insights/ $\mathrm{mgi} / \mathrm{research} /$ natural_resources/the_case_for_ investing_in_energy_productivity

(12) Rodgers, D. Priorization of Energy Efficiency. International Policy Leaders Dialogue, September 25,, 2008, conforme consultado em 6 de dezembro de 2012 no site http://www. slideshare.net/AllianceToSaveEnergy/david-e-rodgers-doe-prioritization-of-energy-efficiency-presentation 